\title{
Morphological, Mechanical, Thermal, Electrical and Rheological Properties of Polycarbonate Composites Reinforced with Surfaces Modified Mica
}

\author{
M. Rahail Parvaiz ${ }^{1}$, P. A. Mahanwar ${ }^{2}$, Smita Mohanty ${ }^{1}$ and Sanjay K. Nayak*1 \\ ${ }^{1}$ Laboratory for Advanced Research in Polymeric Materials, Central Institute of Plastics \\ Engineering \& Technology, Bhubaneswar- 751 024, India. \\ ${ }^{2}$ Department of Polymer Engineering and Technology, University Institute of Chemical \\ Technology, Matunga, Mumbai -400 019, India. \\ * Corresponding Author: larpmcipet@gmail.com
}

\section{ABSTRACT}

The mica fillers reinforced Polycarbonate (PC) composites were fabricated using compression molding technique. The mica surface was chemically modified using vinyltrimethoxy silane and 3-Aminopropyltriethoxy silane. The properties of treated mica PC composites were examined in terms of scanning electron microscopy, thermo gravimetric analysis, differential scanning calorimetry and rheological behavior. The modified mica was observed to disperse more uniformly than the unmodified counterpart. The tensile strength and modulus also improved with treated mica filled PC composites. Polycarbonate (PC) / mica composites were prepared by twin screw extruder at $250{ }^{\circ} \mathrm{C}$. Rheological behavior of PC/mica composites was investigated. The $P C$ / mica composites were characterized by parallel plate rheometer system. As increasing the mica particle size and the content, storage and loss modulus of the PC / mica composites were increased.

Keywords: Particulate reinforced composite; Mechanical; Thermal; Rheological properties; SEM

\section{INTRODUCTION}

Mineral particulate fillers are not only used in polymer composites as substitutes of a relatively costly bulk material, but are also used to improve some properties of neat polymers. The properties of the composites depend upon the characteristics of components, composition, structure and interfacial interactions. The latter factor is affected by the size of the interface and the strength of the interaction. Both, the interface and strength of the interaction could be modified to improve the wettability and adhesion between the components by surface treatment 
with different modifiers such as stearic acid, silane and titanate coupling agents. Silanes are by far the most popular coupling agents for filler surface treatment [1]. Wetting of fillers and the adhesion between the filler and the matrix is governed by the principles of the theory of adhesion based on the surface energy properties of the filler and the matrix, respectively [2]. Surface treatment with reactive silanes is one of the principal methods for converting mineral or inorganic particulates or fibres into the materials bearing covalently bound functional groups, capable of graft formation when used as fillers or reinforcement in the plastics compositions.

Performance of composites depends on the characteristics of the filler, but also on its dispersion and polymer-filler interactions, and more specifically on the properties and thickness of interphase between polymer and filler [3,4]. It is well known that the final performances of the composites depend upon the capabilities of the interphase to transmit the stress from the matrix to the filler. Organosilane is a key element in engineering composites performances as it will affect filler wetting and dispersion through surface energy modification but also allows an optimization of the interphase design. The first challenge of processing a compound is the filler dispersion and organosilanes are widely used in filled polymer composites to help the wetting and dispersion of fillers [5]. The particle agglomerates have to be broken down into smaller parts called aggregates. During mixing of the compound, mechanical shear induces dispersion and distribution of the filler in the matrix. The mechanism for dispersion has been extensively studied $[6,7]$. It is well established that silane, due to its dual reactivity between inorganic and organic functions plays a key role in filler dispersion improvement. The silane treatment clearly decreases the dispersive and specific component of the surface energy but changes also fillerfiller, polymer-filler interactions and agglomerate packing properties $[8,9]$.

The rheological properties of polymer composites including viscoelastic (time or frequency- and temperature-dependent) behavior are of practical importance in relation to processing and characterizing the composite microstructure. The rheological behaviour depends on the material microstructure, the state of the fillers dispersion, the aspect ratio and orientation of the fillers, the interaction between fillers and polymer chains as well as filler-filler interactions. The temperature not only influences the rheological properties of the matrix but it also can affect the state of dispersion of the composites via changes in the particle-particle interactions and in the wettability of the fillers with the matrix.

Mica is a plate like crystalline alumino-silicate and has been widely used as reinforcing filler in polymeric matrices due to its excellent mechanical electrical and thermal properties (10). The commercial delamination of mica may be characterized as wet or dry according to whether the delamination is carried out in a dry state as water. Wet grinding preserves the natural luster and sheen of mica and is normally characterized by clean cut edges, high aspect ratios, smooth surface, and ability to disperse easily [11]. The results of many experimental studies have shown that the addition of mica to thermoplastic matrix improves the mechanical, thermal and dielectric properties. Researches as reported that addition of mica to a polymer system results in significant improvement in tensile strength and modulus. Ruofei et al [12] studied the effect of mica as filler on polymer system and found significant improvement in flexural properties. Grace [13] reported improvement in properties on incorporating mica into plastic. 
Polycarbonate (PC) possesses several distinct properties such as transparency, dimensional stability, flame resistance, high heat distortion temperature, and high impact strength. Therefore, it is an important and widely used engineering thermoplastic. However, PC exhibits high notch sensitivity, and it is susceptible to crazing or cracking on exposure to various solvents. Moreover, PC is relative soft and the surface of the polymer can be easily scratched [14]. These disadvantages limit its use in some applications. The mechanical performance of PC can be improved by the addition of fillers such as fly ash [15], or glass fiber reinforcements [16, 17].

It was shown that coupling agent improves the mechanical properties of mica filled thermoplastics than their uncoupled counterpart [18-23]. Susan and Charles et al. [18] studied the effect of treated mica on polypropylene composites. Newman and Meyer [19] and Verbeek, [20] analyzed the effect of treated mica on polyolefins and found that the incorporation of coupling agent led to significant improvement in Young's modulus. Schreiber et al [21] observed significant changes in rheological behavior on treating mica prior to compounding. Silane and zirconate coupling agent treated mica also showed significant improvements in flexural and dielectric strength, as reported by Collins and Kludt [22] and Pushpa et al. [23] respectively.

In this work, mica particles were introduced into PC compound, as a result of having hydroxyl group on the surface, and vinyl trimethoxy silane (VTMO), AMEO silane were chosen as a coupling agent to improve the properties of the $\mathrm{PC} /$ mica composites. The aim of work is to seek the optimum content of the coupling agent content to be added into the mica for surface modification by considering various properties such as morphological, rheological, mechanical, thermal, electrical properties. The dispersion of modified and unmodified mica in PC matrix was observed by scanning electron microscopy (SEM). The purpose of this article is to investigate the influence of the interaction between matrix and filler on rheological behavior for filled PC composites.

\section{EXPERIMENTAL}

\subsection{Materials}

The commercial Polycarbonate (Lanax 123/R) was obtained from G E Plastic Ltd. Mumbai India. Fillers wet grinded mica of particle size $44 \mu \mathrm{m}$ was supplied by Galaxy Corporation Pvt Ltd., Mumbai India. The silane coupling agent used were vinyltrimethoxysilane (VTMO, Degussa) and 3-Aminopropyltriethoxysilane (AMEO, Degussa), supplied by Aroma Chemical Agencies Pvt Ltd; India.

\subsection{Surface Modification of Mica}

In order to obtain improved interaction between mica and PC matrix, the as-received mica fillers were firstly subjected to surface treatment with vinyltrimethoxysilane (VTMO) and 3Aminopropyltriethoxysilane (AMEO) content was varied from 0 to 1.5 percent by weight (wt $\%$ ) of the mica. The silane solution was prepared by mixing with ethanol. For instance, for silane content of $1 \mathrm{wt} \%, 1 \mathrm{~g}$ of the silane was mixed with $100 \mathrm{ml}$ of ethanol, and then stirred for 30 
minutes. $100 \mathrm{~g}$ of mica were then added into the solution with a further 15 minute stirring, in order to ensure a uniform distribution of the coupling agent on the mica surface. The treated mica was then dried at $100 \pm 5^{\circ} \mathrm{C}$ for $12 \mathrm{hrs}$ in an oven until a constant weight was achieved. Similarly, 0.5 and $1.5 \%$ wt of silane coupling agents on the ash surface were prepared by varying the initial VTMO/AMEO silane contents for $100 \mathrm{~g}$ mica using the same procedure as described above.

\subsection{Composites Preparation}

Polycarbonate, silane treated mica was predried at $80 \pm 5^{\circ} \mathrm{C}$ for $8 \mathrm{hrs}$ prior to compounding. The vinyl trimethoxysilane treated mica $(20 \mathrm{wt} \%)$ were added to PC. The composites were prepared by using melt mixing in co-rotating twin screw extruder with 25:1 L/D ratio (M/S APV Baker, UK, and Model: MP19 PC.). The temperature profiles in barrel were 125, 200, 260, 275, $280^{\circ} \mathrm{C}$ from feed zone to die zone. The screw length to diameter ratio (L/D) was 25:1 and screw speed of $40 \mathrm{rpm}$. The extrudates were water cooled at room temperature, pulled, and palletized. The palletized granules of PC mica composites were predried at $80 \pm 5^{\circ} \mathrm{C}$ for $8 \mathrm{hrs}$. Test specimens were prepared from compression molding in a sheet mold of $180 \times 180 \times 3 \mathrm{~mm}^{3}$ using machine from M/s. Sterling hydraulic Co. Ltd, Mumbai, India. Temperature of mold plate was $280 \pm 5{ }^{\circ} \mathrm{C}$ with cycle of time 15 mins, breathing was done after 5 mins with an interval of 1 min and then kept at $280 \pm 5{ }^{\circ} \mathrm{C}$ temperature and pressure and cooled to $40{ }^{\circ} \mathrm{C}$ under continuous hydraulic pressure of $180 \mathrm{~kg} / \mathrm{cm}^{2}$. Testing samples were prepared according to ASTM standards.

\subsection{Mechanical Testing}

Room temperature tensile properties, including tensile modulus, tensile strength and elongation to break, were determined in accordance with the ASTM D638 taking specimens of dimensions $165 \times 13 \times 3 \mathrm{~mm}^{3}$. The tensile testing were carried out using Universal Tensile Testing Machine (UTM) LR 50K from Lloyds Instrument Ltd. (UK) at a cross head speed of $50 \mathrm{~mm} / \mathrm{min}$. Flexural properties were measured using a three-point bending test method according to ASTM D790 and were carried out on UTM LR 50K from Lloyds Instrument Ltd. (UK); with rectangular bars of dimension $80 \times 12.7 \times 3 \mathrm{~mm}^{3}$. Tests were conducted at a jaw speed of $0.8 \mathrm{~mm} / \mathrm{min}$ at room temperature. Charpy impact test were performed using a $2.7 \mathrm{~J}$ pendulum and striking velocity of $3.46 \mathrm{~m}^{2} / \mathrm{s}$ on an Avery Denison Impact tester (model 6709), according to ASTM D256. The specimen dimension was $127 \times 12.7 \times 3 \mathrm{~mm}^{3}$.

\subsection{Dielectric Strength}

The Dielectric Strength, according to ASTM D 149, was measured using Zaran Instruments (India) with a $3 \mathrm{~mm}$ thick composite disc. The voltage was increased slowly and the voltage at which the current penetrated the sample was noted. The configurations of the instruments were: input: $240 \mathrm{~V}, 50 \mathrm{~Hz}, 1 \mathrm{PH}$; output: 0-50 kV; capacity: $100 \mathrm{~mA}$; rating: $15 \mathrm{~min}$. 


\subsection{Limit Oxygen Index (LOI)}

The LOI was measured as per ASTM D2863-77 using Dynisco Instrument (USA), with specimen dimensions $70 \times 6 \times 3 \mathrm{~mm}^{3}$.

\subsection{Rheological Properties}

The melt rheology of PC as well as their composites was studied using rotational rheometer (RT 10, Haake, Germany). Oscillatory mode was used for rheological study using parallel plate assembly with a sensor having diameter of $35 \mathrm{~mm}$. The dynamic properties i.e. storage modulus, $\mathrm{G}^{\prime}(\mathrm{Pa})$, loss modulus $\mathrm{G}^{\prime \prime}(\mathrm{Pa})$ and phase angle, $\tan \delta=\mathrm{G}^{\prime \prime} / \mathrm{G}^{\prime}$ as a function of frequency, $\omega$ (rad $/ \mathrm{s}$ ) were measured. The frequency of oscillation was varied from 0.01 to $200 \mathrm{rad} / \mathrm{s}$. The rheological characteristics were measured at constant temperature of $280{ }^{\circ} \mathrm{C}$; the samples were predried at $80 \pm 5{ }^{\circ} \mathrm{C}$ before analysis of $\mathrm{PC}$ and its composites.

\subsection{Morphological Examination}

Scanning electron microscopy (SEM) studies of fractured surface of tensile specimen were carried out on Jeol (6380LA, Japan). Specimen was sputter coated with gold to increase surface conductivity. The digitized images were recorded.

\section{RESULT AND DISCUSSION}

\subsection{Microstructure Characterizations}

Scanning electron microscopy (SEM) micrographs were used to examine the morphologies of PC filled with AMEO/VTMO silane treated and untreated mica. A pure PC had a relatively smooth morphology; the morphologies of the fractured composites changed dramatically, and very rough surface was observed. In Figure 1 shows VTMO Silane treated mica/PC composite SEM micrographs shows that mica coming out from the PC matrix. A dark circle region clearly depicts the interaction between the matrix PC and mica. The mica particles encapsulated in the PC matrix shows strong interfacial adhesion between the treated mica and PC. When comparing the untreated mica with AMEO/VTMO Silane treated mica, improved interaction with matrix PC were observed which have been subsequently corroborated with the mechanical findings discussed below.

\subsection{Mechanical Properties}

Figure 2a enumerates the room temperature tensile modulus of the PC treated mica composites. The tensile modulus of both unmodified and modified mica filled PC composites shows a linearly increasing trend with the increasing concentration of silane content. Moreover, the tensile modulus values of the VTMO silane treated mica filled PC composites are higher than those of the AMEO silane treated mica PC composites. It was described above that the modified mica would make denser and more uniform dispersion and less agglomeration in the PC matrix. 
Accordingly, it is convinced that the denser and uniform dispersion and the less agglomeration of the fillers should play a more effective role in the enhancement of the tensile modulus. As for the tensile strength performance of the resulting PC composites, as shown in Figure $2 b$, there are extremes at the filler content of $20 \mathrm{wt} \%$ for both the unmodified and modified mica filled PC composites. The tensile strength increases with increase in concentration of coupling agents up to 1 and $2 \mathrm{wt} \%$ of VTMO silane. Higher concentration (5 wt \%) of coupling agents showed a decrease in tensile strength. In AMEO silane treated mica the tensile strength increased up to 2 wt $\%$ of silane and then decrease but in VTMO silane treated mica tensile strength increased up to $1 \mathrm{wt} \%$ then dropped. Comparing the effect of the surface treatment with VTMO silane on the tensile strength, it is shown that there is significant difference between the modified and unmodified mica filled PC composites.
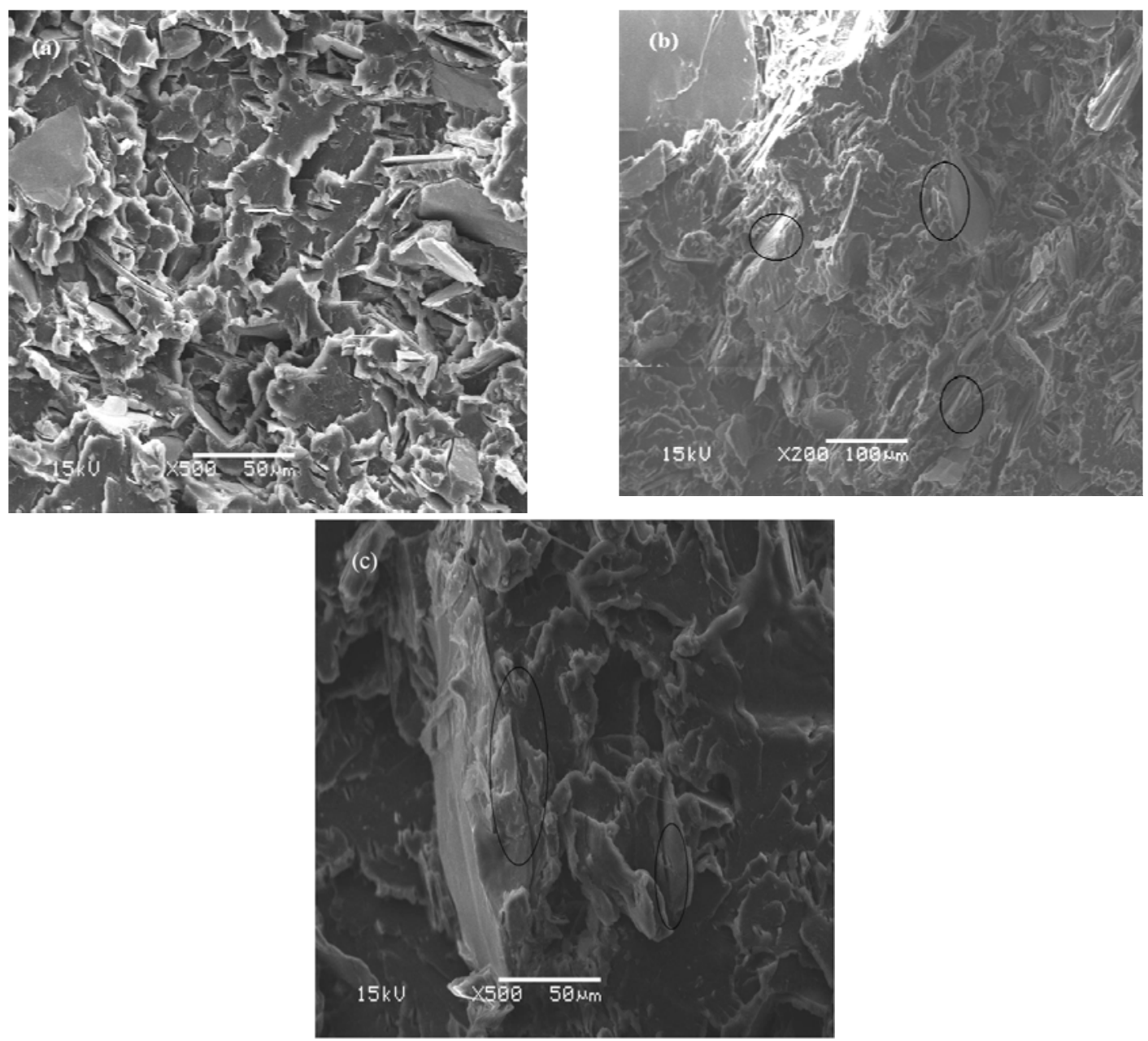

Fig. 1. SEM micrographs taken from the fractured surface of tensile specimens, showing the adhesion between mica (20 wt \%) fillers in the PC matrix: (a) unmodified mica, (b) modified mica with $2 \mathrm{wt} \%$ AMEO silane and (c) modified mica with 2wt $\%$ VTMO silane.

It was observed that elongation at break decreases as concentration of silane of increases. In case of VTMO silane the rate decrease in elongation at break was more than AMEO silane. It is clear 
that the filler matrix interaction is definitely enhanced on the addition of coupling agents. The elongation at break of $20 \mathrm{wt} \%$ loading of untreated and treated mica PC composite are shown in Figure 2c. It was proposed that the inclusion of the inorganic filler into the polymer matrix could reinforce the weakness of the polymer matrix, but it would sacrifice the ductility of the polymer [24].

Figure $2 \mathrm{~d}$ depicts the variation of flexural modulus of untreated and treated mica PC composites. It is seen that flexural modulus increases with increasing concentrations of coupling agents up to $1 \mathrm{wt} \%$ of VTMO silane treated mica addition flexural modulus drastically improved $29 \%$ compared to untreated mica than after which $1 \mathrm{wt} \%$ flexural modules dropped. In case of AMEO silane treated mica flexural modulus increased up to $1 \mathrm{wt} \%$ and then decreased. This change in the phenomenon of variation in flexural modulus of treated and untreated mica composites may be due to an increase in interfacial interaction of filler matrix due to incorporation of coupling agents.
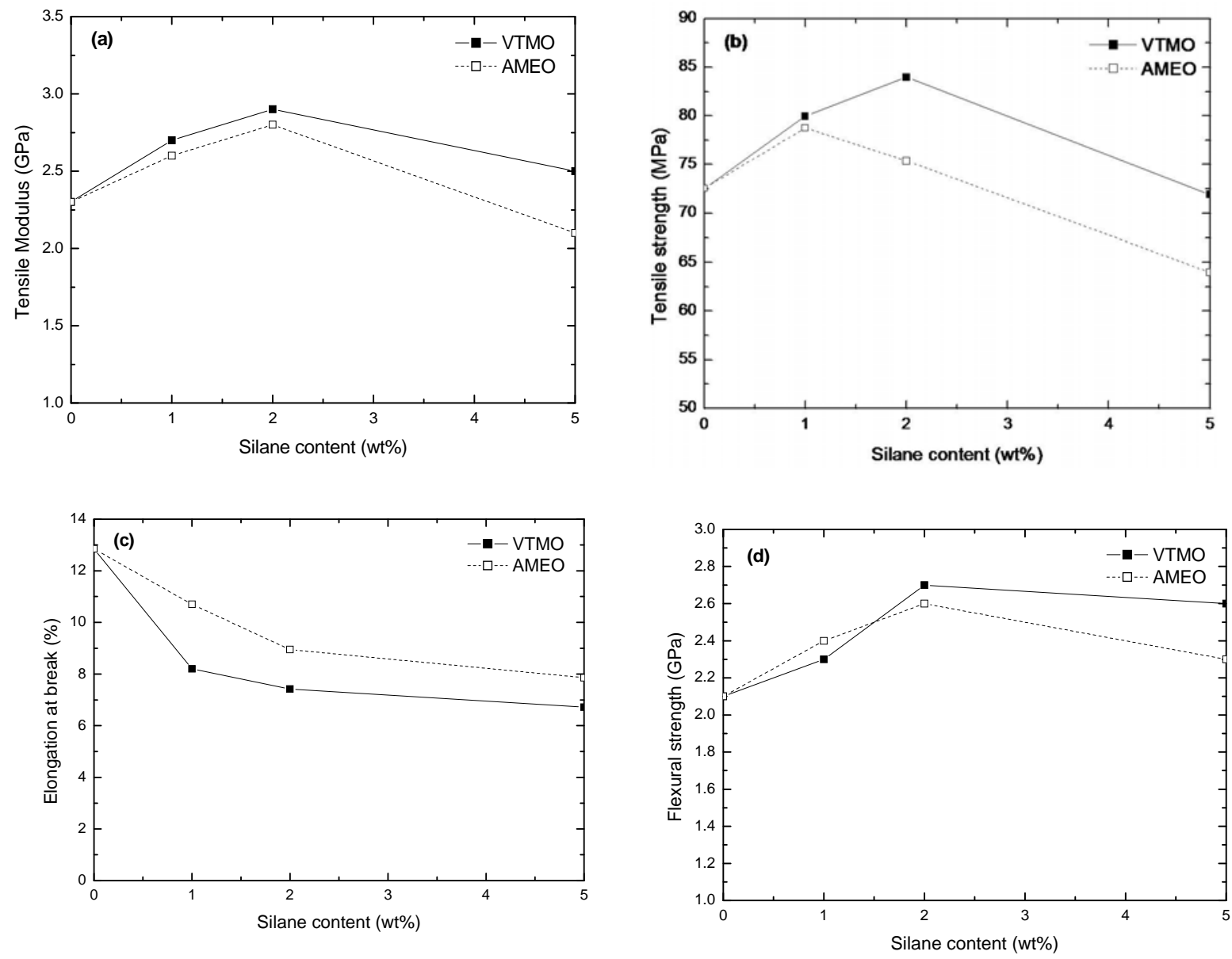

Fig. 2. Variations of: (a) Tensile modulus, (b) Tensile strength, (c) Elongation at break and (d) Flexural modulus of the PC composites as a function of the silane content in wt\%. 


\subsection{Dielectric Strength}

Figure 3 depicts the variation in dialectic strength with varying concentration of coupling agents. In VTMO Silane treated mica the dielectric strength increases as compared to AMEO silane of PC mica composites which may be due to the proper encapsulation of filler particles of the matrix which provides same continuity for current flow.

\subsection{Limiting Oxygen Index (LOI)}

The Limiting oxygen index (LOI) is the minimum percentage of oxygen in an oxygen-nitrogen mixture that will initiate and support burring for three minutes [25]. LOI increased with the increase in the concentration silane. The LOI increased $11 \%$ by incorporation of $5 \mathrm{wt} \% \mathrm{VTMO}$ saline treated mica thus decreasing the flammability of composites. In case of AMEO saline treated mica increased up to $2 \mathrm{wt} \%$ and then remain constant at higher concentration (5 wt \%) as shown in Figure 4.

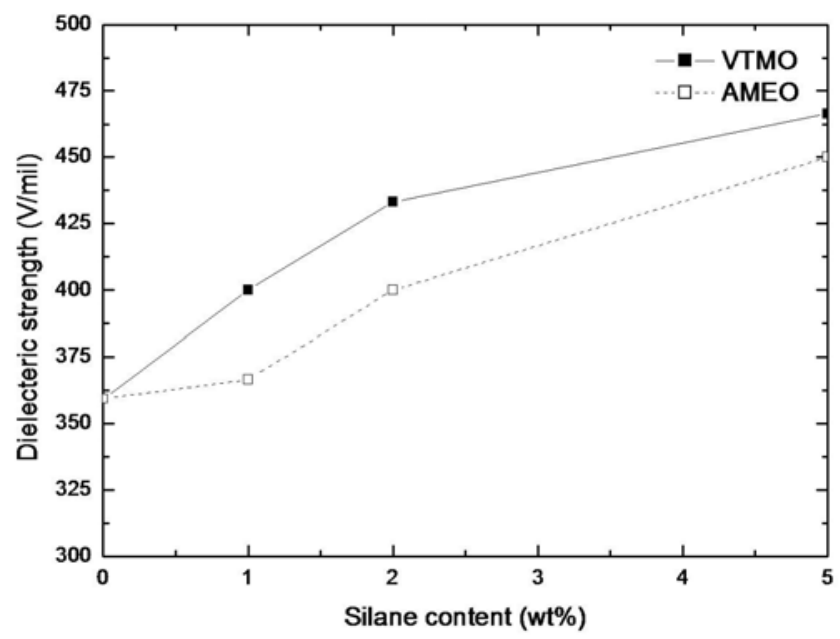

Fig. 3. Variations of: dielectric strength of the PC composites as a function of the silane content in $\mathrm{wt} \%$.

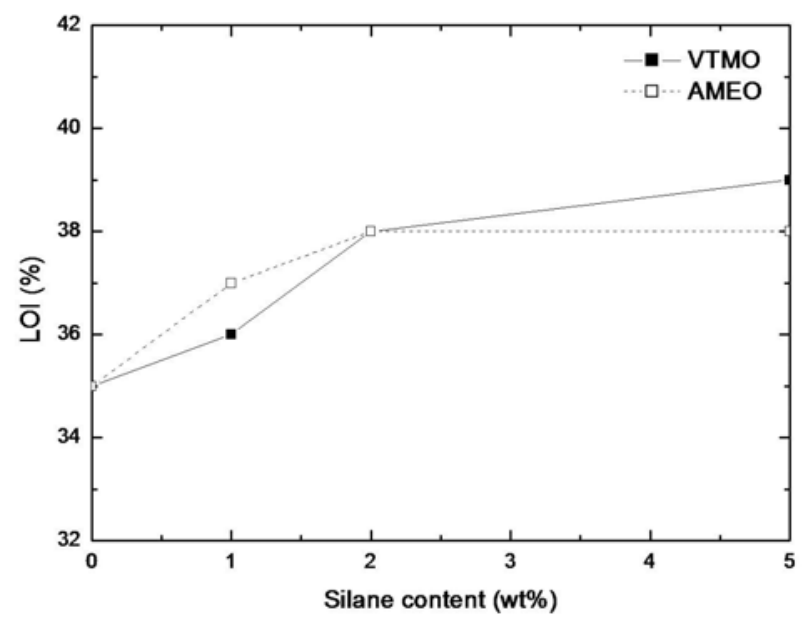

Fig. 4. Variations of: LOI of the PC composites as a function of the silane content in wt\%. 


\subsection{Rheological Properties}

\subsubsection{Steady shear viscosity (n)}

The results of the steady shear tests also confirm the effect of coupling agents. Figure 5 gives relationship of steady viscosity $(\eta)$ and shear rate $(\gamma \cdot)$ for composites exposed to different surface-treatment. It can be seen that surface-treatment of fillers results in the change of rheological behavior of composites, especially in low $\omega$.

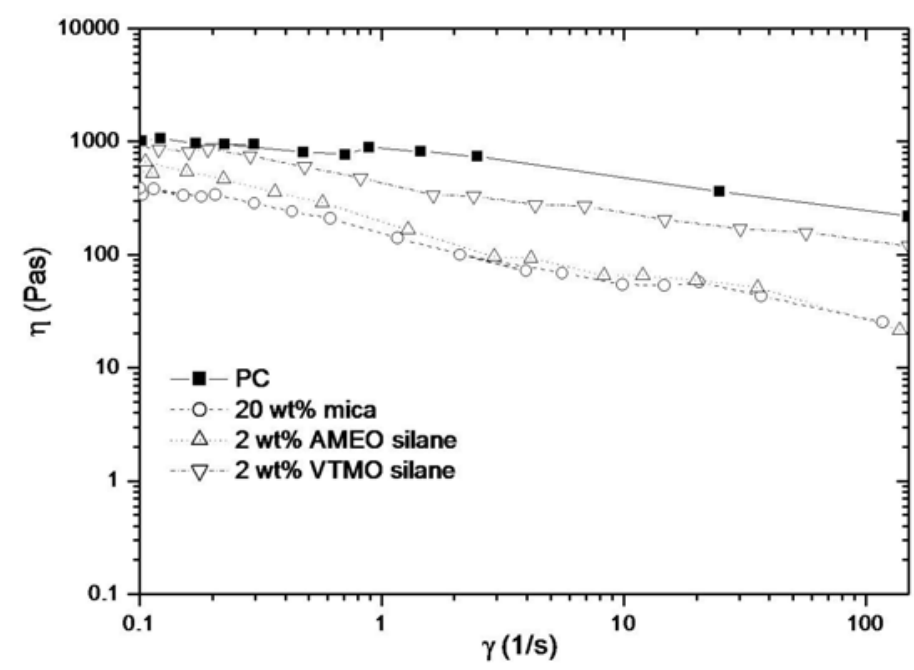

Fig. 5. Relationship between shear viscosity $\left(\eta^{*}\right)$ and frequency $(\omega)$ for composites exposed to different surface-treatment

The virgin PC, the values of $\eta$ of composites are higher than those of PC untreated mica and PC treated mica composite, ranking as $\mathrm{PC}>20 \mathrm{wt} \%$ mica $>2 \mathrm{wt} \%$ AMEO silane $>2 \mathrm{wt} \% \mathrm{VTMO}$ silane. Also, as compared with that of virgin PC, $\eta$ of filled polymer presents the characteristic of non-Newtonain fluids at lower shear rate $\gamma$. and higher shear rate $\gamma$ - shows shear-thinning behavior. The reason for this is owed to formation of an active organic mono-layer, induced by the silane coupling agent. On the other hand, the mono-layer has the effect of lubricant on the flow. Hence, the formation of chemical link between main chain in matrix and fillers strongly improved the movement of PC chain, leading to lower $\eta$ for $2 \mathrm{wt} \%$ VTMO silane treated mica.

\subsubsection{Complex viscosity $\left(\eta{ }^{*}\right)$}

The $\eta^{*}$ is important for determining rheological properties. The real part of $\eta^{*}$ is an energy dissipation term similar to the imaginary part of the complex modulus. The frequently dependence on melt $\eta^{*}$ of VPC as well as $20 \mathrm{wt} \%$ mica, AMEO and VTMO silane treated mica PC composites is shown in Figure 6. The typical Newtonain behavior of all samples can be observed through decrease in $\eta^{*}$ with increase in frequency. The Newtonain behavior of the PC and composites at high frequency is due to the impact of high frequency is due to the impact of 
high frequency which results in weak filler matrix interface there by reducing the viscosity. Incorporation of $20 \mathrm{wt} \%$ of mica in PC matrix decreases the viscosity which can be due to mica flakes that increased segmental mobility of polymer chain. The change in viscosity of treated mica PC composites due to enhanced of filler matrix interaction. The maximum improvement in $\eta^{*}$ in observed in case of VTMO silane treated mica PC composites. Generally silane groups is reach with the filler surface and polymer matrix and filler improved the movement of $\mathrm{PC}$ chain leading to lower $\eta^{*}$ for VTMO silane treated mica PC composites.

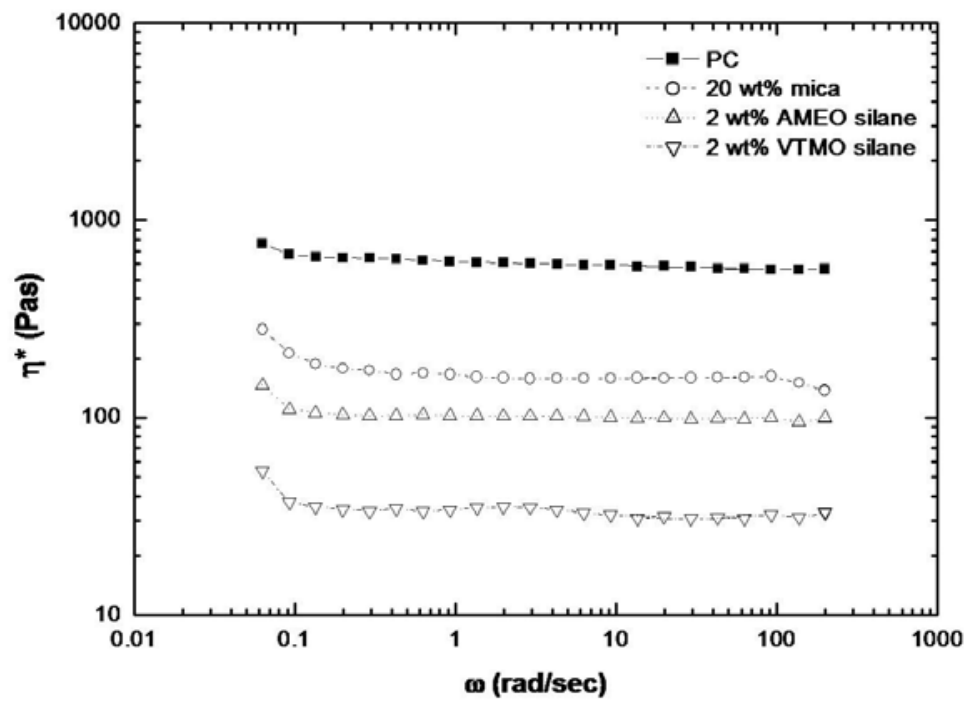

Fig. 6. Relationship between complex viscosity $\left(\eta^{*}\right)$ and frequency $(\omega)$ for composites exposed to different surface-treatment

\subsubsection{Storage modulus $\left(G^{\prime}\right)$}

In general, the increase of dynamic viscoelastic functions in the low frequency $(\omega)$ range is related to the extent of heterogeneity for the filled polymers. The higher the $G^{\prime}$, the more heterogeneous is the system. In other words, the better the value of $G^{\prime}$ approaches that of the virgin $\mathrm{PC}$, the higher is the level of compatibility of the interface [29]. Figure 7 shows $\omega$ dependence of $G^{\prime}$ for AMEO and VTMO silane treated mica PC composites at $280^{\circ} \mathrm{C}$. The increase in $G^{\prime}$ is mainly due to stiffness imparted by the mica that allows efficient stress transfer. Further, addition of silane results in additional decrease in the modulus of the matrix polymer thus indicating improved interfacial interaction between the mica and PC. However, $G^{\prime}$ for VTMO is lower than that of AMEO silane treated mica, especially in low $\omega$. It is well accepted whether the slope of $\log G^{\prime}$ vs $\log \omega$ at low $\omega$ is close to 2 or not, as defined in rheology, is responsible for the existence of heterogeneous or homogeneous structure in multi-component polymers $(26,27)$. Accordingly, the results above indicated that the surface-treatment of fillers improved the interaction between $\mathrm{PC}$ and mica; and furthermore, with respect to the improvement of interface compatibility between filler and PC matrix, the effect of VTMO silane was more effective than that of AMEO silane. 


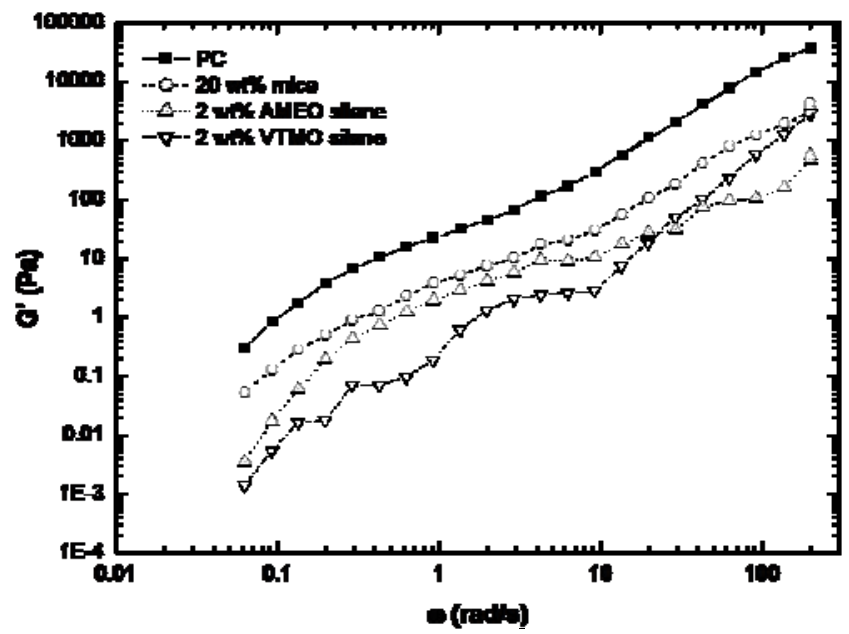

Fig. 7. Relationship between dynamic storage modulus $G^{\prime}$ and frequency $\omega$ for composites exposed to different surface-treatment

\section{CONCLUSION}

The modified mica filled PC composite shows better interaction in mica/ PC matrix more uniform filler dispersion, and it appears the smaller inter-planer spacing of the PC phase. However, the unmodified mica filled PC composites do not reveal this effect. The modified mica filled PC composites exhibit higher tensile strength and modulus values than those of the unmodified ones. The reinforcement of modified mica increase flexural modulus by $29 \%$ at 2 $\mathrm{wt} \%$ VTMO silane and 23\% at 2wt $\%$ AMEO silane respectively. The $2 \mathrm{wt} \%$ concentration of VTMO silane is found to be optimized in PC mica composites on the basis of mechanical properties. The PC composite filled with the VTMO silane treated mica would show higher dielectric strength and LOI at the filler contents of interest as compared with those of the AMEO silane treated mica, suggesting that the better interaction of filler and matrix, well dispersion of the mica could reduce its domain size and make more improvement on the stiffness of the PC matrix. The change complex viscosity $\left(\eta^{*}\right)$ and dynamic modulus $\left(G^{\prime}\right)$ of the composite and PC matrix, especially those for systems treated with silane, which was attributed to the interfacial adhesion enhancement. In overall performance VTMO silane treated mica showed better reinforcement properties than AMEO silane treated mica.

\section{REFERENCES}

[1] Fekete E., Moczo J,. Pukanszky B., 2004, "Determination of the surface characteristics of particulate fillers by inverse gas chromatography at infinite dilution: a critical approach." J.Colloid Interfaces Sci., Vol. 269(10), pp. 143-152.

[2] Metin D., Tihminlioglu F., Balkose D., Ulku S., 2004, “The effect of interfacial interactions on the mechanical properties of polypropylene/natural zeolite composites." Composite Part A, Vol. 35(1), pp. 23-32. 
[3] Maiti S.N., Lopez B.H., 1992, "Tensile properties of polypropylene/kaolin composites." J.Appl Polym Sci., Vol. 44(2), pp. 353-360.

[4] Kim J K., Mai Y W., 1993, "Interfaces in Composites, Materials Science and Technology, Structure and Properties of Composites" Germany, VCH, pp. 229-289.

[5] George Wypych., 2004, Handbook of Fillers. 2nd Ed. Plastics Design Library, pp. 545546.

[6] Boyle J., Manas-Zloczower I., Feke D., 2004, "Influence of Particle Morphology and Flow Conditions on the Dispersion Behavior of Fumed Silica in Silicone Polymers." Part. Syst. Charact., Vol. 21(3), pp. 205-212.

[7] Dubnikova I L., Oshmyan V G., Gorenberg A Y., 1997, J Mater Sci., Vol. 32(6), pp. 161322.

[8] Scurati A., Manas-Zloczower I., Feke D., 2002, Chem. Technol., Vol. 75, pp. 725- 738.

[9] Bose S., Mahanwar P. A., 2006, J Appl Polym Sci., Vol. 99, pp. 266-72.

[10] Katz H S., Milewsk J. V., Eds., 1978, Handbook of fillers and Reinforcement for plastic. Van Nostrond Reinhold: New York.

[11] Woodhoms R T., M Xanthos., 1978, In Handbook of fillers and Reinforcement for plastic, Katz, HS; Milewsk JV Eds, Van Nostrond Reinhold: New York.

[12] Sheppherd P D., Golemba F J., Maine F W., 1978, In Handbook of fillers and Reinforcement for plastic, Van Nostrond Reinhold: New York.

[13] Berlin A A., Volfson S A., Enikolopian N S., Negnatov S S., 1986, Principles of polymer composites. Berlin: Springer.

[14] Kohlman W G., Petrie S P., 1995, Adv Polym Technol, Vol. 14, pp. 111.

[15] Kayano Y., Kerkkula H., Paul D R., 1998, Polymer, Vol. 39, pp. 821.

[16] Chrysostomou A., Hashemi S., 1996, J Mater Sci., Vol. 3, pp. 1183.

[17] Ho K C., Hwang J R., Doong J L., 1996, Polym and Polym Compos, Vol. 4, pp. 563.

[18] Susan E T., Charles E C., 1982, J Appl Polym Sci., Vol. 27, pp. 4493-4500.

[19] Newman S, Meyer F. Mica composites of improved strength. J. Polym Compos (1980); $1: 37-43$.

[20] Verbeek C J R., 2003, Mater Lett, Vol. 57, pp. 1919- 924.

[21] Schrieber H P., Tewari Y B., Wertheimer M R., 1976, J Appl Polym Sci., Vol. 20, pp. 2663-2673.

[22] Collins W T., Kludt J L., 1975, Proceedings of the 30th Annual Technical Conference, Reinforced Plastics/Composites Institute/ SPI, Sec 7D.

[23] Pushpa B., Jha N K., Anand K., 1995, J Appl Polym Sci., Vol. 56, pp. 133 -1347.

[24] Suryasarathi Bose., Mahanwar P A., 2005, Polym Eng Sci., Vol. 45, pp. 1479-1486.

[25] Molcolm P., 1990, Stevens. Polymer chemistry an introduction. Second edition, Oxford university press. New York, pp. 174-75.

[26] Yan Xia CAO., Miao DU., Qiang Zheng., 2004, Chin. J. Mat. Res., Vol. 15(5), pp. $567-$ 570.

[27] Qiang Zheng., Hong Guo Hu., Xiao Le Tao., 2004, Chinese Chemical Letters, Vol. 15(1), pp. $71-73$. 